\title{
Parâmetros bioquímicos para avaliação da função hepática em bezerras sadias, da raça holandesa, no primeiro mês de vida
}

\author{
Biochemical parameters to evaluate liver function of healthy female holstein calves \\ during the first month of live
}

\author{
Fernando José Benesi ${ }^{1}$ Marta Lizandra do Rêgo Leal ${ }^{2}$ Júlio Augusto Naylor Lisbôa ${ }^{3}$ \\ Clarisse Simões Coelho ${ }^{4}$ Regina Mieko Sakata Mirandola ${ }^{5}$
}

\section{RESUMO}

Para o estabelecimento de valores bioquímicos de referência utilizados para avaliar a função hepática de bezerras sadias, da raça Holandesa, utilizaram-se amostras de soro sangüineo de 300 animais, distribuídos por 15 grupos experimentais, de acordo com a idade, no primeiro mês de vida. Os constituintes bioquímicos estudados foram as bilirrubinas (total , conjugada e livre) e as enzimas gama glutamiltransferase (GGT), aspartato aminotransferase (AST) e creatina quinase (CK). Considerou-se na análise dos resultados a influência do fator etário. As taxas séricas das bilirrubinas demonstraram maiores valores no primeiro dia de vida (BT$1,360 \mathrm{mg} / \mathrm{dl}$; $B C-0,150 \mathrm{mg} / \mathrm{dl}$ e $B L-1,175 \mathrm{mg} / \mathrm{dl}$ ), apresentando a seguir diminuições significativas até os trinta dias de vida (BT-0,350mg/dl; BC-0,050mg/dl e BL-0,300mg/dl). A atividade sérica da GGT foi máxima entre 16 e 24 horas de idade (945,00UI/L), sendo seguida por diminuições dos valores, de forma significativa a partir do $11^{\circ}$ dia de vida (86,00UI/), atingindo valores descritos para animais adultos aos 30 dias de idade (24,00UI/). As enzimas AST e CK apresentaram taxas máximas no primeiro dia de vida (AST-27,50UI/L e CK73,00UI/L), seguidas por diminuições e pequenas oscilações até o final do periodo analisado (AST- 19,00UI/L e CK-
41,50UI/L). A influência do fator etário provou-se significativa para todos os constituintes bioquímicos estudados.

Palavras-chaves: função hepática, bezerros, neonatos, bioquímica clínica.

\section{ABSTRACT}

Three hundred healthy female Holstein calves were used for assess the liver function throughout the first month of life. The following serum biochemical variables were analysed: bilirrubin (total, direct and indirect) and the activities of gamma glutamyltransferase (GGT), aspartate aminotransferase (AST) and creatine kinase (CK). The influence of age on the biochemical values was also studied. The bilirrubin values had highest levels on the $1^{\text {st }} d$ of life (BT-1.360mg/dl; BC-0.150mg/ dl e $B L-1.175 \mathrm{mg} / \mathrm{dl}$ ) and then showed a continuing decrease until the $30^{\text {th }} d$ of life (BT-0.350mg/dl; BC-0.050mg/dl e BL$0.300 \mathrm{mg} / \mathrm{dl}$ ). The serum GGT activities were at they highest point between the $16^{\text {th }}$ to $24^{\text {th }} h(945.00 U I / L)$. There was a downward trend from the $11^{\text {th }} d(86.00 U I /)$, presenting the lowest activity at the $30^{\text {th }} d(24.00 U I /)$ similar to the activities usually found in healthy adult dairy cattle. The activities of AST and CK were higher at the $1^{\text {st }} d$ of life (AST- 27.50UI/L e

\footnotetext{
${ }^{1}$ Medico Veterinário, Professor Associado, Livre-Docente, Departamento de Clínica Médica da Faculdade de Medicina Veterinária e Zootecnia da Universidade de São Paulo (FMVZ/USP). Av. Orlando Marques de Paiva, 87, 05508-000, São Paulo, SP - Brasil, febencli@usp.br Autor para correspondência.

${ }^{2}$ Medico Veterinário, Mestre pelo Departamento de Clínica Médica, FMVZ/USP.

${ }^{3}$ Medico Veterinário, Professor Adjunto, Doutor, Departamento de Clínicas Veterinárias, Universidade Estadual de Londrina, PR, Brasil.

${ }^{4}$ Medico Veterinário, Mestrando do Departamento de Clínica Médica da FMVZ/USP.

${ }^{5}$ Técnico de Nível Superior do Departamento de Clínica Médica, FMVZ/USP.
} 
CK- 73.00UI/L) declining from then on (AST-19.00UI/L e CK41.50UI/L). Ageing showed a significant influence on all the biochemical variables studied.

Key words: liver function, calves, newborn, clinical biochemistry.

\section{INTRODUÇÃO}

As altas taxas de mortalidade de bezerros recém-nascidos, observadas durante o primeiro mês de vida, representam uma das principais perdas na atividade pecuária (SANTOS \& GRONGNET, 1989). Contribui para a redução desta mortalidade o conhecimento das variáveis fisiológicas de bezerros nos aspectos clínico e laboratorial, para a elucidação, reconhecimento e diferenciação dos estados mórbidos que acometem esses animais. Além disso, esses dados são essenciais para garantir o atendimento clínico desses neonatos, visando minorar as perdas econômicas na criação bovina (BENESI, 1993).

A avaliação clínica dos neonatos, quanto à identificação de adequada adaptação orgânica ou à presença de enfermidades, exigem em muitas situações, além do exame físico do animal, o emprego de provas laboratoriais complementares, como provas bioquímicas séricas, que permitam analisar o estado funcional de diversos órgãos, entre os quais é especialmente importante o fígado. Todavia, para que se possa usar em sua plenitude os resultados de tais exames, faz-se necessário a existência de valores de referência para cada uma das provas utilizadas, considerando-se fatores de variabilidade como a espécie animal, raça, sexo, idade e influências do manejo a que os animais são submetidos.

Apesar da importância do conhecimento do perfil bioquímico sérico para a correta interpretação dos resultados, no que se refere à avaliação da função hepática em neonatos bovinos, poucas foram as pesquisas nacionais dedicadas ao assunto destacando-se aquelas realizadas por OLIVEIRA (196770); FAGLIARI etal.(1996); BORGES(1997); FAGLIARI et al. (1998) e FEITOSA (1999). A análise destes trabalhos indicou que, na sua maioria, foram delineados com a utilização de pequeno número de amostras, insuficiente para o estabelecimento de valores de referência ou então, sem o detalhamento necessário para estudar a influência do fator etário sobre as provas bioquímicas avaliadas.

Para suprir-se a carência dessas informações na literatura, delineou-se esta pesquisa com o objetivo de estabelecer valores de referência no soro sangüíneo de bezerras sadias, da raça Holandesa, no primeiro mês de vida, bem como estudar a possível variabilidade sob influência do fator etário para as seguintes provas bioquímicas utilizadas para avaliar a função hepática: bilirrubinas séricas (total, conjugada e livre) e as enzimas aspartato aminotransferase (AST), gama glutamiltransferase (GGT) e creatina quinase (CK).

\section{MATERIAL E MÉTODOS}

Foram utilizadas 300 bezerras sadias, da raça Holandesa, com até 30 dias de vida, oriundas de 17 propriedades produtoras de leite dos tipos A e B localizadas em 8 municípios no Estado de São Paulo. As bezerras foram distribuídas por 15 grupos experimentais, cada um com 20 animais, de acordo com a faixa etária: do nascimento até 8 horas de vida; 8 -| 16 horas; 16 -| 24 horas; 2 dias; 3 dias; 4 dias; 5 dias; 5 - 7 dias; 7 -| 9 dias; 9 -| 11 dias; 11 -| 13 dias; 13 -| 15 dias; 15 - 20 dias; 20 -| 25 dias e 25 -| 30 dias. Os animais selecionados para o experimento ainda não haviam sido submetidos a programas de premunição contra Babesia spp. e Anaplasma sp., e foram considerados clinicamente sadios, após o exame clínico (DIRKSEN et al., 1993). Foram excluídos do experimento os animais que apresentaram volume globular inferior a $25 \%$ ou superior a $40 \%$.

As amostras de sangue foram colhidas por punção da veia jugular, com a utilização de tubos de colheita a vácuo siliconizados ${ }^{\mathrm{a}}$ sem anticoagulante. Após a colheita, as amostras foram centrifugadas ${ }^{\mathrm{b}}$ por cerca de 15 minutos, sendo o soro sangüíneo, separado e fracionado em 3 alíquotas. A primeira delas foi utilizada, imediatamente após a obtenção do soro, para quantificar as bilirrubinas e as outras duas armazenadas sob congelamento a $-20^{\circ} \mathrm{C}$ até o momento da execução dos demais testes bioquímicos. As bilirrubinas total e conjugada foram quantificadas por colorimetria direta, utilizando-se kit comercial $^{c}$ (JENDRASSIK \& GROF, 1938). A bilirrubina livre foi então calculada por diferença entre os valores obtidos para as bilirrubinas total e conjugada. A atividade enzimática da GGT foi avaliada com o uso de analisador bioquímico automático ${ }^{\mathrm{d}}$, em $405 \mathrm{~nm}$, utilizando-se kit comercial $^{\mathrm{e}}$ (SZASZ ,1969). A atividade da AST foi determinada através de kit comercial ${ }^{\mathrm{f}}$, em analisador bioquímico automático, em comprimento de onda de 340nm (BERGMEYER, 1974). A CK sérica foi quantificada em analisador bioquímico automático, em comprimento de onda de 340nm, utilizando-se kit comercial ${ }^{\mathrm{g}}$ (SCHIMID e von FORSTNER, 1986).

Por não apresentarem distribuição Gaussiana, segundo o teste de Kolmogorov-Smirnov, os resultados obtidos foram submetidos à prova não paramétrica de Kruskal-Wallis e ao teste de Dunn para comparação entre pares de medianas com $5 \%$ de 
significância $(\alpha=0,05)$, (BERQUÓ et al., 1980). As analises estatísticas foram efetuadas com o auxílio de um programa estatístico computadorizado (Sigma Stat, 1989).

\section{RESULTADOS E DISCUSSÃO}

Os resultados obtidos para os parâmetros bioquímicos utilizados para avaliar a função hepática em bezerras hígidas, da raça Holandesa, no primeiro mês de vida, são apresentados nas tabelas 1 e 2 .

\section{Bilirrubinas séricas (total, conjugada e livre)}

Os valores das medianas observados para a bilirrubina total sérica nas bezerras holandesas nas diferentes faixas etárias variaram no intervalo entre 0,350 e $1,360 \mathrm{mg} / \mathrm{dl}$, como mostra a tabela 1 , quando comparados com os apresentados na literatura, foram semelhantes àqueles demonstrados nos trabalhos de KURTZ \& WILLET (1991), LUMSDEN et al. (1980), bem como àqueles reportados por ADAMS et al. (1993) em animais, oriundos de gestação simples, com 24 e 48 horas de vida. Tiveram, todavia, maiores magnitudes do que os valores reportados por MAACH et al. (1991); ADAMS et al. (1993) FAGLIARI et al. (1998) em ani- mais ao nascimento. Observou-se ainda, que foram menores quando comparados com aqueles descritos por ADAMS et al. (1993) em animais, oriundos de gestação gemelar, com 24 e 48 horas de vida, e por FAGLIARI et al. (1998) em animais com 15 e 30 dias de vida.

Os teores séricos observados para a bilirrubina conjugada nas bezerras holandesas do nascimento até os 30 dias de idade apresentaram pequena magnitude e variaram entre 0,050 e $0,150 \mathrm{mg}$ / dl (Tabela 1) e ao serem comparados com os resultados de trabalhos que constam da literatura, revelaram-se menores que os obtidos por LUMSDEN et al. (1980) e MARY et al. (1995). As taxas séricas de bilirrubina livre (Tabela 1), por sua vez, assemelharam-se às descritas por LUMSDEN et al. (1980), sendo maiores do que as apresentadas por MARY et al. (1995). Este tipo de bilirrubina foi o principal responsável pela variação observada para a bilirrubina total, tendo suas concentrações intervalo entre 0,300 e $1,175 \mathrm{mg} / \mathrm{dl}$. As diferenças de magnitude das taxas de bilirrubinas séricas assinaladas no confronto com os resultados apresentados na literatura podem ser decorrentes do delineamento experimental, utilizando valores médios e amostras dependentes, verificado na grande maioria dos trabalhos confrontados.

Tabela 1 - Valores de medianas (Md), percentis de 25\% $\left(\mathrm{P}_{25}\right)$ e $75 \%\left(\mathrm{P}_{75}\right)$, e contraste entre grupos verificados para a bilirrubina total (BT), bilirrubina conjugada $(\mathrm{BC})$ e bilirrubina livre $(\mathrm{BL})$ no soro sangüíneo de bezerras sadias, da raça Holandesa, agrupadas de acordo com a idade no primeiro mês de vida.

\begin{tabular}{|c|c|c|c|c|c|c|c|c|c|c|c|}
\hline \multirow{2}{*}{ grupo } & \multirow{2}{*}{ idade } & \multirow{2}{*}{$\mathrm{n}^{\circ}$} & \multicolumn{3}{|c|}{ BT (mg/dl) } & \multicolumn{3}{|c|}{$\mathrm{BC}(\mathrm{mg} / \mathrm{dl})$} & \multicolumn{3}{|c|}{$\mathrm{BL}(\mathrm{mg} / \mathrm{dl})$} \\
\hline & & & $\mathrm{Md}$ & $\mathrm{P}_{(25)}$ & $P_{(75)}$ & $\mathrm{Md}$ & $P_{(25)}$ & $P_{(75)}$ & $\mathrm{Md}$ & $\mathrm{P}_{(25)}$ & $P_{(75)}$ \\
\hline 1 & $0-\mid 8 h$ & 20 & $0,920^{\mathrm{ab}}$ & 0,715 & 1,27 & $0,125^{\mathrm{ab}}$ & 0,080 & 0,180 & $0,785^{\mathrm{ab}}$ & 0,615 & 1,120 \\
\hline 2 & $8-16 h$ & 20 & $1,030^{\mathrm{ab}}$ & 0,825 & 1,42 & $0,130^{\mathrm{abc}}$ & 0,100 & 0,165 & $0,945^{\mathrm{ab}}$ & 0,670 & 1,255 \\
\hline 3 & $16-24 h$ & 20 & $1,360^{\mathrm{a}}$ & 0,975 & 1,71 & $0,150^{\mathrm{a}}$ & 0,130 & 0,190 & $1,175^{\mathrm{a}}$ & 0,790 & 1,530 \\
\hline 4 & $2 d$ & 20 & $0,780^{\mathrm{abc}}$ & 0,575 & 1,63 & $0,145^{\mathrm{abc}}$ & 0,080 & 0,185 & $0,690^{\mathrm{abc}}$ & 0,480 & 1,365 \\
\hline 5 & $3 d$ & 20 & $0,755^{\text {abcd }}$ & 0,445 & 1,65 & $0,140^{\mathrm{abcd}}$ & 0,065 & 0,190 & $0,635^{\mathrm{abcd}}$ & 0,380 & 1,250 \\
\hline 6 & $4 d$ & 20 & $0,460^{\text {cde }}$ & 0,410 & 0,60 & $0,100^{\text {abcde }}$ & 0,065 & 0,130 & $0,385^{\text {cde }}$ & 0,340 & 0,500 \\
\hline 7 & $5 d$ & 20 & $0,520^{\text {bcde }}$ & 0,445 & 0,68 & $0,080^{\text {abcde }}$ & 0,060 & 0,115 & $0,430^{\text {bcde }}$ & 0,365 & 0,570 \\
\hline 8 & $5-17 d$ & 20 & $0,460^{\text {cde }}$ & 0,390 & 0,51 & $0,075^{\text {bcde }}$ & 0,045 & 0,115 & $0,360^{\mathrm{de}}$ & 0,330 & 0,420 \\
\hline 9 & $7-9 d$ & 20 & $0,510^{\text {cde }}$ & 0,385 & 0,56 & $0,060^{\text {bcde }}$ & 0,045 & 0,090 & $0,430^{\text {cde }}$ & 0,310 & 0,495 \\
\hline 10 & $9-11 d$ & 20 & $0,460^{\text {cde }}$ & 0,390 & 0,61 & $0,075^{\text {bcde }}$ & 0,055 & 0,115 & $0,390^{\mathrm{de}}$ & 0,295 & 0,505 \\
\hline 11 & $11-13 d$ & 20 & $0,395^{\mathrm{e}}$ & 0,355 & 0,51 & $0,065^{\mathrm{cde}}$ & 0,035 & 0,100 & $0,320^{\mathrm{e}}$ & 0,285 & 0,430 \\
\hline 12 & $13-15 d$ & 20 & $0,355^{\mathrm{e}}$ & 0,320 & 0,42 & $0,055^{\mathrm{de}}$ & 0,030 & 0,090 & $0,305^{\mathrm{e}}$ & 0,275 & 0,350 \\
\hline 13 & $15-20 d$ & 20 & $0,415^{\mathrm{e}}$ & 0,355 & 0,45 & $0,060^{\mathrm{de}}$ & 0,040 & 0,075 & $0,350^{\mathrm{e}}$ & 0,280 & 0,400 \\
\hline 14 & $20-\mid 25 d$ & 20 & $0,395^{\mathrm{e}}$ & 0,320 & 0,46 & $0,070^{\mathrm{de}}$ & 0,035 & 0,100 & $0,330^{\mathrm{e}}$ & 0,270 & 0,375 \\
\hline 15 & $25-30 d$ & 20 & $0,350^{\mathrm{e}}$ & 0,280 & 0,44 & $0,050^{\mathrm{e}}$ & 0,035 & 0,085 & $0,300^{\mathrm{e}}$ & 0,225 & 0,385 \\
\hline
\end{tabular}

a, b, c, d, e . Medianas com letras não coincidentes denotam diferença estatística significativa $-\mathrm{p} \leq 0,05$. 
A influência do fator etário sobre as variações das taxas séricas das bilirrubinas total, conjugada e livre (Tabela1) foi demonstrada através das observações de valores máximos nas bezerras com 16 a 24 horas de vida, seguidos por diminuições progressivas e significativas dos valores até os 30 dias de idade, quando foram registrados teores mínimos (Tabela1). Um comportamento similar ao observado ao longo deste estudo para as concentrações de bilirrubina total também foi evidenciado por KURTZ \& WILLET (1991); MAACH et al. (1991); ADAMS et al. (1993) e FAGLIARI et al. (1998). No entanto, não houve possibilidade de comparação da variação dos resultados obtidos para as bilirrubinas conjugada e livre com aqueles verificados na literatura, em virtude da ausência de pesquisas estudando estes componentes no sangue de neonatos bovinos.

As maiores taxas séricas da bilirrubina total, constatadas nas primeiras 24 horas de vida das bezerras, já haviam sido registradas em neonatos primatas, humanos e eqüinos também no primeiro dia de vida (GARTNER et al., 1977; LEE \& GARTNER., 1986 e KAPLAN \& PESCE, 1989), nos quais foram consideradas como sendo conseqüência das baixas concentrações da enzima uridine-difosfato-glicuronil- transferase, responsável pela conjugação da bilirrubina livre no fígado, elevando suas concentrações na circulação sangüínea. No entanto, SHOAF et al. (1987) constataram uma alta atividade da uridine-difosfatoglicuronil-transferase em bezerros com um dia de vida, o que sugere não ser esta a causa das maiores concentrações de bilirrubina total nas primeiras 24 horas de vida desses neonatos.

MAACH et al. (1991); ADAMS et al. (1993) e MARY et al. (1995) cogitaram que tal fato ocorria em virtude de uma maior destruição dos eritrócitos em decorrência da troca da hemoglobina fetal pela forma adulta. Apesar de a bilirrubina livre ter sido a principal responsável pelos maiores valores observados no total das bilirrubinas no primeiro dia de vida dos neonatos estudados nesta pesquisa, deve-se ressaltar que os animais selecionados para formar os grupos etários tinham volume globular superior a 25 e inferior a $40 \%$, o que permite inferir-se ser diminuta a probabilidade de que o aumento da bilirrubina total no primeiro dia de vida dos bezerros tenha sido conseqüência de uma maior metabolização da hemoglobina proveniente da destruição dos eritrócitos.

Restou deste modo, a hipótese de KANEKO et al. (1997) que atribuíram esse comportamento das

Tabela 2 - Valores de medianas $(\mathrm{Md})$, percentis de $25 \%\left(\mathrm{P}_{25}\right)$ e $75 \%\left(\mathrm{P}_{75}\right)$, e contraste entre grupos verificados para a gama glutamiltransferase (GGT), aspartato aminotransferase (AST) e creatina quinase (CK) no soro sangüíneo de bezerras sadias, da raça Holandesa, agrupadas de acordo com a idade no primeiro mês de vida.

\begin{tabular}{|c|c|c|c|c|c|c|c|c|c|c|c|}
\hline \multirow[t]{2}{*}{ grupo } & \multirow[t]{2}{*}{ idade } & \multirow[t]{2}{*}{$\mathrm{n}^{\circ}$} & \multicolumn{3}{|c|}{ GGT (UI/l) } & \multicolumn{3}{|c|}{ AST (UI/l) } & \multicolumn{3}{|c|}{ CK (UI/l) } \\
\hline & & & Md & $\mathrm{P}_{(25)}$ & $P_{(75)}$ & $\mathrm{Md}$ & $\mathrm{P}_{(25)}$ & $P_{(75)}$ & Md & $\mathrm{P}_{(25)}$ & $\mathrm{P}_{(75)}$ \\
\hline 1 & $0-\mid 8 h$ & 20 & $200,00^{\text {abcd }}$ & 7,500 & 751,00 & $13,50^{\mathrm{c}}$ & 11,00 & 26,50 & $73,00^{\mathrm{a}}$ & 51,50 & 190,50 \\
\hline 2 & $8-16 h$ & 20 & $776,00^{\mathrm{a}}$ & 149,00 & 1735,00 & $24,00^{\mathrm{ab}}$ & 19,00 & 33,00 & $61,00^{\mathrm{ab}}$ & 42,00 & 143,00 \\
\hline 3 & $16-24 h$ & 20 & $945,00^{\mathrm{a}}$ & 343,00 & 1240,00 & $27,50^{\mathrm{a}}$ & 21,00 & 32,00 & $65,00^{\mathrm{ab}}$ & 37,50 & 100,50 \\
\hline 4 & $2 d$ & 20 & $665,00^{\mathrm{a}}$ & 185,00 & 840,00 & $25,00^{\mathrm{a}}$ & 24,00 & 30,50 & $39,00^{\mathrm{abc}}$ & 30,50 & 90,50 \\
\hline 5 & $3 d$ & 20 & $270,00^{\mathrm{ab}}$ & 194,00 & 440,00 & $20,50^{\mathrm{a}}$ & 14,50 & 28,00 & $28,50^{\text {abcde }}$ & 18,00 & 81,00 \\
\hline 6 & $4 d$ & 20 & $238,50^{\mathrm{abc}}$ & 130,50 & 283,50 & $16,00^{\mathrm{bc}}$ & 13,50 & 17,50 & $18,50^{\mathrm{e}}$ & 12,00 & 27,00 \\
\hline 7 & $5 d$ & 20 & $186,50^{\mathrm{abc}}$ & 85,00 & 332,50 & $16,00^{\mathrm{bc}}$ & 14,00 & 21,50 & $19,00^{\mathrm{de}}$ & 14,50 & 29,50 \\
\hline 8 & $5-17 d$ & 20 & $140,50^{\mathrm{abc}}$ & 86,50 & 277,00 & $15,00^{\mathrm{bc}}$ & 14,00 & 21,00 & $21,00^{\text {cde }}$ & 16,50 & 29,50 \\
\hline 9 & $7-9 d$ & 20 & $125,00^{\mathrm{abc}}$ & 78,00 & 253,50 & $14,50^{\mathrm{c}}$ & 12,00 & 17,00 & $32,00^{\text {bcde }}$ & 19,50 & 53,50 \\
\hline 10 & $9-11 d$ & 20 & $176,50^{\text {abcd }}$ & 59,00 & 274,00 & $15,00^{\mathrm{c}}$ & 14,00 & 18,50 & $33,00^{\text {abcde }}$ & 27,00 & 52,00 \\
\hline 11 & $11-13 d$ & 20 & $86,00^{\text {bcde }}$ & 45,50 & 112,50 & $16,00^{b c}$ & 13,50 & 19,00 & $48,00^{\mathrm{abcd}}$ & 29,00 & 58,00 \\
\hline 12 & $13-15 d$ & 20 & $73,50^{\text {bcde }}$ & 48,50 & 85,00 & $16,50^{\mathrm{bc}}$ & 14,50 & 19,00 & $44,50^{\mathrm{abcd}}$ & 28,00 & 51,00 \\
\hline 13 & $15-20 d$ & 20 & $60,50^{\text {cde }}$ & 47,50 & 77,00 & $15,50^{\mathrm{bc}}$ & 14,00 & 18,00 & $36,50^{\text {abcde }}$ & 25,00 & 46,00 \\
\hline 14 & $20-\mid 25 d$ & 20 & $25,50^{\mathrm{de}}$ & 18,50 & 45,00 & $18,50^{\mathrm{abc}}$ & 15,50 & 20,50 & $39,00^{\text {abcde }}$ & 29,00 & 51,00 \\
\hline 15 & $25-30 d$ & 20 & $24,00^{\mathrm{e}}$ & 17,00 & 34,00 & $19,00^{\mathrm{abc}}$ & 14,50 & 23,00 & $41,50^{\mathrm{abc}}$ & 36,50 & 54,50 \\
\hline
\end{tabular}

a, b, c, d, e . Medianas com letras não coincidentes denotam diferença estatística significativa - p $\leq 0,05$.

Ciência Rural, v. 33, n. 2, mar-abr, 2003. 
bilirrubinas a uma menor concentração da ligadina, que é uma das proteínas responsáveis pelo transporte da bilirrubina não conjugada para o fígado, como sendo a causa mais provável das maiores taxas de bilirrubina livre em recém-nascidos.

\section{Gama glutamiltransferase sérica (GGT)}

A atividade da GGT sérica nas bezerras holandesas em diferentes faixas etárias (Tabela 2) exibiu um valor mediano máximo entre 16 e 24 horas pósnascimento, sendo posteriormente seguido por uma diminuição significativa a partir de 11 dias de vida, atingindo uma taxa mínima aos trinta dias de idade. De modo geral o comportamento demonstrado pela GGT foi concorde com aqueles observados em bezerros por MAACH et al. (1991); FAGLIARI et al. (1998); BORGES (1997) e FEITOSA et al. (1999). A ocorrência de maiores valores de GGT em bezerras no primeiro dia de vida, também foi citada por BOUDA et al. (1980); BRAUN et al. (1982); BOYD (1989); MAACH et al. (1991); PERINO (1993); FAGLIARI et al. (1996) e FAGLIARI et al. (1998). A razão dessas taxas aumentadas foi atribuída à absorção desta enzima a partir do colostro ingerido, no qual está presente em altas concentrações, como já havia sido relatado por BOYD (1989), PERINO (1993) e FAGLIARI et al. (1996). A rápida diminuição da atividade sérica da GGT observada a partir de dois dias de vida ocorreu, provavelmente, pela degradação desta enzima (THOMPSON \& PAULI, 1981).

A elevada atividade sérica da GGT, nos primeiros vinte dias de vida de bezerros, limita sua utilização para a avaliação funcional do fígado nesse período, particularmente em bezerros neonatos que consumiram adequadamente o colostro nas primeiras horas de vida (BRAUN et al., 1982). O confronto dos valores de medianas obtidos para a GGT sérica com aqueles referidos na literatura permitiu evidenciar que em bezerras com até oito horas de vida os valores foram maiores do que os referidos por BOUDA et al. (1980); BOYD (1989), MAACH et al. (1991), PERINO (1993); FAGLIARI et al. (1996) e FAGLIARI et al. (1998). Tal constatação deve-se ao momento de amostragem das bezerras nesta pesquisa, realizada com um período médio de 4 horas pós-nascimento, quando já haviam mamado e absorvido a enzima do colostro, elevando assim, as concentrações séricas de GGT (SOBIECH et al., 1974 e BRAUN et al., 1978). Essa discrepância dos resultados com maiores valores assinalados nesta pesquisa, pode ser justificada pelo maior consumo de colostro propiciado por um período mais longo de seu fornecimento, durante 48 horas, e que adicionalmente as bezerras permaneciam mamando diretamente em suas mães nas primeiras 24 horas de vida.
As taxas séricas de GGT, obtidas nas bezerras analisadas nesta pesquisa, a partir de oito horas de vida, assemelharam-se àquelas apresentadas por MAACH et al. (1991) em animais com 4, 7 e 15 dias de vida; por FAGLIARI et al. (1996) em bezerros zebuínos com dois dias de vida, assim como por BORGES (1997) em animais que receberam 2 litros de colostro. Por serem menores, não concordaram com os valores relatados por BOUDA et al. (1980), e por serem maiores, diferiram em alguns momentos das concentrações descritas por BOYD (1989); PERINO (1993); por BORGES (1997) em animais que receberam 4 litros de colostro; por FAGLIARI et al. (1998) e FEITOSA et al. (1999).

\section{Aspartato aminotransferase sérica (AST)}

Os teores séricos da AST, apresentados na tabela 2, variaram significativamente sob influência do fator etário, com observação de um valor mediano mínimo entre o nascimento e oito horas de vida, seguido por aumentos significativos até uma taxa máxima detectada às 24 horas de vida. A partir dos dois dias de idade os valores diminuíram apresentando pequenas oscilações praticamente até o trigésimo dia de avaliação. Comportamento semelhante ao obtido ao longo desta pesquisa para a atividade sérica da AST também foi constatado por BOUDA et al. (1980); KURTZ \& WILLET (1991); MAACH et al. (1991); ADAMS et al. (1993); FAGLIARI et al. (1996) e FAGLIARI et al. (1998).

Os valores medianos observados para a atividade enzimática da AST, no presente estudo (Tabela 2), por serem menores discordaram dos mencionados por BOYD (1989); KURTZ \& WILLET (1991); MAACH et al. (1991); ADAMS et al. (1993); FAGLIARI et al. (1996) e FAGLIARI et al. (1998). Diferiram ainda dos resultados apresentados por BOUDA et al. (1980), por serem maiores, sendo, no entanto, similares aos valores obtidos por OLIVEIRA (1967-70). O nível máximo de AST verificado entre 16 e 24 horas pós-nascimento já havia sido descrito por BOUDA et al. (1980); BOYD(1989); KURTZ \& WILLET (1991); MAACH et al. (1991); ADAMS et al. (1993); FAGLIARI et al. (1996) e FAGLIARI et al. (1998). Segundo KURTZ \& WILLET (1991) e MAACH et al. (1991), tal fato estaria relacionado à ingestão de colostro. No entanto, SVERRE \& BORGE (1970) e BOYD (1989) constataram aumentos desta enzima no primeiro dia de vida de bezerros que ingeriram ou não o colostro, sugerindo que a concentração de AST era mínima ou até mesmo ausente no colostro. Endossando tais observações, FAGLIARI et al. (1996) demonstraram não haver correlação significativa entre os níveis séricos de AST e de gamaglobulina em bezerros com até 6 dias de vida. Nenhum desses autores cogitaram, 
todavia, sobre a possibilidade do aumento das concentrações séricas da AST em bezerros neonatos, estar relacionada a alterações ou imaturidade hepáticas, uma vez que todas as células possuem AST, apresentando-se em maiores concentrações nas células hepáticas e musculares esqueléticas. Segundo HAGIWARA (1982), desde que se excluam lesões musculares, o aumento da AST em bovinos poderia ser interpretado como decorrente de alteração hepática.

$\mathrm{O}$ aumento nos teores séricos da AST nos bezerros neonatos poderia estar relacionado a injúrias sofridas pela musculatura durante o parto, ao início ou ao aumento da atividade muscular (BOYD, 1989). Contudo, não há evidências concretas na literatura para esclarecer esse aumento da AST, sendo necessária, como feito nesta pesquisa, a avaliação conjunta desses resultados com os de enzima mais especifica $(\mathrm{CK})$ para indicar que a origem fosse muscular ou hepática.

\section{Creatina quinase sérica (CK)}

Apesar da importância da CK como indicadora de lesões musculares (COLVILLE, 1992.) e diferenciadora de aumentos da AST, quanto à origem muscular ou hepática destes, poucos foram os trabalhos encontrados na literatura consultada elaborados com o intuito de determinar os valores de referência da CK em bezerros ou que a estudaram em conjunto com a AST, particularmente, nos primeiros trintas dias de vida, o que dificultou o confronto e comparação dos resultados obtidos nesta pesquisa. O perfil de variação da atividade enzimática da CK obtido neste estudo (Tabela 2) apresentou-se com um valor sérico máximo entre o nascimento e oito horas de vida, sendo este mantido com pequenas variações até as 24 horas pósnascimento, quando as taxas diminuíram progressivamente e de modo significativo do $4^{\circ}$ ao $9^{\circ}$ dia de vida, seguindo então com ligeiro aumento e oscilações até o final dos 30 dias de observação.

Os valores medianos das concentrações séricas de CK nas diferentes faixas etárias foram inferiores àqueles relatados por BOYD (1989); ADAMS et al. (1993) e MARY et al. (1995), assemelhando-se apenas aos valores encontrados por ANDERSON et al. (1976) em animais com mais de 2 dias de vida. Não puderam ser adequadamente comparados aos valores descritos por LUMSDEM et al. (1980) que só apresentaram o comportamento das variações dos resultados, sem expressá-los numericamente pelos valores médios.

As maiores magnitudes da CK demonstradas no primeiro dia de vida das bezerras também foram reportados nos trabalhos de ANDERSON et al. (1976); BOYD (1989) e ADAMS et al. (1993). Segundo esses autores, as taxas mais elevadas observadas nesta fase de vida dos bezerros estariam relacionadas ao início ou aumento da atividade muscular ou à presença de injurias musculares sofridas durante o parto. Ao considerar-se conjuntamente os resultados da AST e o da CK (Tabela 2), verifica-se comportamento similar das enzimas nas primeiras 24 horas de vida das bezerras avaliadas neste estudo, podendo-se afirmar que a AST, neste período inicial de vida, tinha provável origem muscular.

\section{CONCLUSÕES}

Os constituintes bioquímicos avaliados na presente pesquisa sofrem variações influenciadas pelo fator etário. $\mathrm{O}$ comportamento das bilirrubinas séricas (total, conjugada e livre) caracterizado por seus maiores valores no primeiro dia de vida e decréscimo com evolução da idade, necessita de novos estudos para a elucidação de suas razões. Em decorrência da elevada atividade da GGT nos primeiros 20 dias de vida de bezerros, a utilização desta enzima para a avaliação funcional do fígado fica limitada, particularmente nos animais que consomem adequadamente o colostro. Os maiores valores da AST e da CK, observados nas primeiras 24 horas de vida, refletem um aumento da atividade muscular nos bezerros neonatos.

\section{AGRADECIMENTO}

À Fundação de Amparo à Pesquisa do Estado de São Paulo, FAPESP, pelo apoio financeiro.

\section{FONTES DE AQUISIÇÃO}

\author{
${ }^{a}$ Vacutainer ${ }^{\circledR}$ Becton Dickson \\ ${ }^{b}$ Excelsa Baby-modelo-208N-FANEM \\ 'Bilirrubina Celm \\ ${ }^{\mathrm{d} B a y e r-T e c h n i c o n ~ m o d e l o ~ R A-100 ~}$ \\ ${ }^{\mathrm{e} B o e h r i n g e r}$ Manheim-artigo $\mathrm{n}^{\mathrm{o}} 1087.584$ \\ ${ }^{\mathrm{f} B o e h r i n g e r}$ Manheim-artigo $\mathrm{n}^{\circ} 1087.550$ \\ ${ }^{\mathrm{g}}$ Boehringer Manheim-artigo $\mathrm{n}^{\mathrm{o}} 1087.533$
}

\section{REFERÊNCIAS BIBLIOGRÁFICAS}

ADAMS, R. et al. Physiologic differences between twin and single born beef calves in the first two days of life. Cornell Veterinarian, v.83, n.1, p.13-29, 1993.

ANDERSON, P. H.; BERRETT, S.; PATTERSON, D. S. P. The significance of elevated plasma creatine phosphokinase active in muscle disease of cattle. Journal Comparativy Phatology, v.86, n.4, p.531-538, 1976.

BENESI, F.J. Síndrome asfixia neonatal dos bezerros. Importância e avaliação crítica. Arquivos da Escola de Medicina Veterinária da Universidade Federal da Bahia, v.16, n.1, p.38-48, 1993.

Ciência Rural, v. 33, n. 2, mar-abr, 2003. 
BERGMEYER, H.U. Methoden der enzymatischen analyse. 3. Aufl. Weirhein: Verlag Chemie, 1974. Bd.I, p.769.

BERQUÓ, E.S; SOUZA, J.P; GOTLIEB, L.D. Bioestatística. São Paulo : EPU, 1980. 325p.

BOUDA,J. et al. The activities of got, gamma-gt, alkaline phosphatase in blood plasma of cows and their calves from fed buckets. Acta Veterinária Brno, v.49, n.3-4, p.193-198, 1980.

BOUDA, J; JAGOS, P. Biochemical and hematological reference values in calves and their significance for health control. Acta Veterinária Brno, v.53, n.3-4, p.193-198, 1984.

BORGES, A.S. Avaliação da eficácia da administração de plasma por via intravenosa, como tratamento da falência de transferência de imunidade passiva em bezerros da raça Holandesa. 1997. 84f. Dissertação (Mestrado em Clínica Veterinária) - Faculdade de Medicina Veterinária e Zootecnia, Universidade de São Paulo.

BOYD, J. W. Serum enzyme changes in newborn calves fed colostrum. Veterinary Clinical Pathology, v.18, n.2, p.47$51,1989$.

BRAUN, J.P. et al. Blood and tissue distribution of gamma glutamyltransferase in calves. Journal Dairy Science, v.61, n.5, p.596-599, 1978 .

BRAUN, J.P. et al. Earl variations of blood plasma gama glutamyl transferase in newborn calves- A test of colostrum intake. Journal Dairy Science, v.65, n.11, p.2178-2181, 1982.

COLVILLE, J. Laboratory procedures for veterinary technicians. 2.ed. Califórnia : American Veterinary, 1992. 601p.

DIRKSEN, G; GRÜNDER, H-D; STÖBER, M. Exame clínico dos bovinos. 3.ed. Rio de Janeiro : Guanabara Koogan, 1993. $419 \mathrm{p}$.

FAGLIARI, J.J. et al. Relação entre o nível sérico de gamaglobulinas e as atividades de gama glutamiltransferase, fosfatase alcalina e aspartato aminotransferase de bezerros recém-nascidos. Arquivo Brasileiro de Medicina Veterinária e Zootecnia, v.48, n.2, p.105-112, 1996.

FAGLIARI, J.J. et al. Constituintes sangüíneos de bovinos recém-nascidos das raças Nelore (Bos indicus) e Holandesa (Bos taurus) e de bubalinos (Bubalus bubalis) da raça Murrah. Arquivo Brasileiro de Medicina Veterinária e Zootecnia, v.50, n.3, p.253-262, 1998.

FEITOSA, F.L.F. et al. Relação entre a concentração de imunoglobulinas colostrais e a transferência de imunidade passiva para bezerros da raça Holandesa após ingestão voluntária de colostro. Ciência Veterinária nos Trópicos, v.2, n.3. p.160-168, 1999 .

GARTNER, L.M. et al. Development of bilirubin transport and metabolism in the newborn rhesus monkey. Journal Pediatric, v.90, n.4, p.513-531, 1977.
HAGIWARA, M.K. Bioquímica clínica. In: BIRGEL, E.H.; BENESI, F.J. Patologia clínica veterinária. 2.ed. São Paulo : Sociedade Paulista de Medicina Veterinária, 1982. p. 89-130.

JENDRASSIK, L; GROF, P. Vereinfachte photometrische methoden zur Bestimmung des Blutbilirubins. Biochemische Zeutschrift, v.297, n.1-2, p. 81-89, 1938

KANEKO, J.J; HARHEY, I.W; BRUSS, M.L. Clinical biochemistry of domestic animal. 5.ed. San Diego : Academic, 1997. 932p.

KAPLAN, L.A.; PESCE, A.J. Clinical chemical-theory, analysis and correlation. 2.ed. Philadelphia : Mosby, 1989. $1147 \mathrm{p}$.

KURTZ, M.M; WILETT, L.B. Carbohydrate, enzyme and hematology dynamics in newborn calves. Journal Dairy Science, v.74, n.7, p.2109-2118, 1991.

LEE, K; GARTNER, L. M. Fetal bilirubin metabolism and neonatal jaundice. In: OSTROW, J.D. (Ed.). Liver: normal function and disease, pt. 4, bile pigments and jaundice; molecular, metabolic and medical aspects. New York : Marcel Dekker, 1986. p.373-378

LUMSDEN, J.H.; MULLEN, K; ROWE, R. Hematology and Biochemistry reference values for female Holstein cattle. Canadian Journal of Comparative Medicine, v. 144, n.1, p.24-31, 1980.

MAACH, L; GRÜNDER, H.D; FAIO, A Hämozytologische und hämobiochemische Untersuchungen bei schwarzbunten, Klinisch gesunden Aufzuchtkälbern in Marokko. Deutsche Tierärztliche Wochenschrift, v.98, n.3, p.94-102, 1991.

MARY, L.G. et al. Icterus in bob veal calves and its association with lack of colostrum intake and high serum creatine kinase activity. American Journal of Veterinary Research, v.56, n.11, p.1506-1512, 1995 .

OLIVEIRA, E .R. Níveis das transaminases glutâmico pirúvica e glutâmico oxalacética no soro de bovinos Holstein- Friesian. Arquivo de Biologia e Tecnologia, v.13, p.5-19, 1967-70.

PERINO, L.J; SUTHERLAND, R.L; WOOLEN, N.E. Serum gama glutamyltransferase activity and protein concentration at birth and after sucking in calves with adequate and inadequate passive transfer of immunoglobulin G. American Journal of Veterinary Research, v.54, n.1, p.56-59, 1993

SANTOS, G.T; GRONGNET, J. Transmissão da imunidade passiva colostral em ruminantes. Gado Holandês, São Paulo, v. 56, n. 178, p.17-30, 1989

SCHIMID, M; von FORSTNER. Laboratory testing in the veterinary medicine diagnosis and clinical monitoring. Mannhein : Boehringer, 1986. 253p. 